\title{
DECISIONS
}

\section{Painful varicocele in an infertile man}

\author{
James A. Forster MB ChB MD, C. Shekhar Biyani MBBS MS
}

See also the practice article by Arrabal-Polo and Merino-Salas on page 323 and at www.cmaj.ca/lookup/doi/10.1503/cmaj.121253

A 30-year-old man presents to his primary care physician with a 12-month history of discomfort within the left side of his scrotum that increases during the day, and an inability to conceive. Examination shows palpable dilated veins in his left hemiscrotum, which become more pronounced with the Valsalva manoeuvre.

\section{What is the most likely diagnosis?}

The patient has a varicocele, which is an abnormal, tortuous dilatation of the pampiniform plexus of testicular veins. It occurs in 10\%-15\% of men, rising to about $25 \%$ of men with an abnormal semen analysis. ${ }^{1}$ Many varicoceles develop in adolescence, and up to $90 \%$ are leftsided. ${ }^{2}$ Most varicoceles are painless and idiopathic. It has been postulated that they arise because of a lack of venous valves, subsequent reflux and raised testicular venous pressure. Increased spermatic DNA damage has been shown in patients with varicoceles.

\section{What features are important on history and physical examination?}

A focused history should elicit the duration and timing of the swelling, the nature of pain and previous surgery. Whether the patient has primary or secondary infertility (i.e., no or previous conceptions) and the duration of attempts to conceive should be clarified, as well as other risk factors for male infertility. Risk factors include a history of infection, undescended testis, inguinoscrotal surgery, genital trauma or testicular torsion, chemo- or radiotherapy, smoking, recreational drug use and prescribed drugs such as nitrofurantoin and sulfasalazine, as well as some congenital and endocrine disorders. ${ }^{2}$

Examination should be in a warm room, with the patient in a standing, then supine, position. Abdominal examination is necessary because of the small risk of a varicocele presenting secondary to a retroperitoneal malignancy, such as renal carcinoma. In this situation, the varicocele is usually on the right, the patient is older and the varicocele does not "empty" when the patient lies flat. Testicular morphology, consistency, size and symmetry should be assessed. Causes of intrascrotal swelling are listed in Box 1.2

Varicoceles are often classified according to the system by Hudson and colleagues. ${ }^{4}$ Varicoceles that are visible and palpable are classified as grade 3, those that are palpable when the patient stands but without the Valsalva manoeuvre are grade 2, and those that are not visible and only palpable during the Valsalva manoeuvre are grade $1 .^{4}$ In this patient, a grade 2 varicocele is observed, with no other relevant findings.

\section{Does this patient require investigations?}

Because this patient is concerned about infertility, semen analysis is required and should be repeated if abnormal. ${ }^{5}$ Patients with pain (such as this patient) and those with an abnormal testicular examination require colour Doppler scrotal ultrasonography to accurately assess the testis and volume measurement. If a retroperitoneal malignancy is suspected (i.e., in an older patient with a right-sided varicocele), abdominal ultrasonography is indicated. Routine use of ultrasonography is not required for patients with an asymptomatic left-sided varicocele. ${ }^{5}$

\footnotetext{
Box 1: Differential diagnosis for intrascrotal swelling ${ }^{2}$

Testicular

- Testicular cancer, infection (e.g., orchitis, epididymo-orchitis)

Epididymal

- Cyst, spermatocele, infection (e.g., epididymitis)

Spermatic cord

- Inguinal hernia, cord lipoma, cord hydrocele Other

- Varicocele, hydrocele, hematocele, idiopathic scrotal edema
}

Competing interests: C. Shekhar Biyani declares that his institution has received payment from Ethicon and that he has received an educational grant from GlaxoSmithKline to attend annual meetings.

This article has been peer reviewed.

Correspondence to:

C. Shekhar Biyani, shekharbiyani@hotmail.com

CMAJ 2013. DOI:10.1503 /cmaj.121445 


\section{Should he be referred to a urologist?}

This patient should be referred nonurgently, ideally to a urologist with an interest in andrology or infertility. Whereas most varicoceles can be managed with assessment and reassurance, referral to a urologist is suggested for adults with infertility, pain or discomfort, or a suspicion of malignant disease. Children with a varicocele should be referred, as well as adolescents with bilateral varicoceles, diminished testicular growth or a large varicocele causing emotional upset. ${ }^{5,6}$

\section{Will surgery help his pain?}

When indicated, varicocele ablation can be performed via a surgical route (open, microsurgical or laparoscopic ligation of the internal spermatic veins) or radiologically guided transvenous embolization. The latter is a minimally invasive approach requiring only sedation or local anesthesia. There are no randomized controlled trials comparing treatment modalities; a single case series on microsurgical techniques has shown partial and complete resolution of pain in $20 \%$ and $72 \%$ of patients, respectively.

\section{If the results of a semen analysis are abnormal, will treatment improve his likelihood of conception?}

This is a contentious matter, because of differing conclusions in the literature as to whether varicocele treatment simply improves semen parameters or actually increases pregnancy rates. Although the Canadian Urological Association does not cover this subject in its guidelines, the American Urological Association recommends offering repair of grades 1-3 varicoceles for men with abnormal semen analysis results (whether or not he is attempting conception) and recommends repair in adolescents with a varicocele associated with reduced ipsilateral testicular size. ${ }^{5}$ The European Association of Urology recommends that varicocele repair be considered in the case of grades 1-3 varicoceles with oligospermia and at least 2 years of otherwise unexplained infertility, and it is recommended for adolescents with progressive failure of testicular development. ${ }^{6}$ A 2009 Cochrane review found no evi-

\section{Physician resources}

- American Urological Association. Report on Varicocele and Infertility. 2001. Available: www.auanet.org/content/media/varicoceleinfertility.pdf

- European Association of Urology Guidelines on Male Infertility: The 2012 Update. Available: www.europeanurology.com/article/S0302-2838(12) 00524-6/pdf/European+Association+of+Urology+Guidelines+on+Male +Infertility\%3A+The+2012+Update dence that treatment of varicocele improves conception rates; however, this review has been criticized because men with normal semen analysis and with subclinical varicocele were included. ${ }^{8}$ The most recent meta-analysis reported a nonsignificant improvement in pregnancy rates with treatment of varicocele with a combined odds ratio of 2.23 (95\% confidence interval 0.86-5.78, $p=0.09$ ), suggesting further trials are needed to answer this important clinical question. ${ }^{9}$

\section{References}

1. The influence of varicocele on parameters of fertility in a large group of men presenting to infertility clinics. World Health Organization. Fertil Steril 1992;57:1289-93.

2. Schneck FX, Bellinger MF. Abnormalities of the testes and scrotum and their surgical management. In: Wein AJ, Kavoussi LR, Novick AC, et al. Campbell-Walsh urology. 9th ed. Philadelphia (PA): W.B. Saunders; 2007:3761-98.

3. Zini A, Dohle G. Are varicoceles associated with increased deoxyribonucleic acid fragmentation? Fertil Steril 2011;96:1283-7.

4. Hudson RW, Perez Marrero RA, Crawford VA, et al. Hormonal parameters in incidental varicoceles and those causing infertility. Fertil Steril 1986;45:692-700.

5. American Urology Association. American Urological Association report on varicocele and infertility: an AUA best practice policy and ASRM Practice Committee Report. Linthicum (MD): The Association; 2001. Available: www.auanet.org/resources .cfm?ID=466 (accessed 2012 Aug. 12).

6. European Association of Urology. European Association of Urology guidelines on male infertility. Arnhem (the Netherlands): The Association; 2012. www.uroweb.org/guidelines (accessed 2012 Aug. 12).

7. Kim SO, Jung H, Park K. Outcomes of microsurgical subinguinal varicocelectomy for painful varicoceles. J Androl 2012; 33:872-5.

8. Evers JH, Collins J, Clarke J. Surgery or embolisation for varicoceles in subfertile men. Cochrane Database Syst Rev 2009; (21):CD000479.

9. Baazeem A, Belzile E, Ciampi A, et al. Varicocele and male factor infertility treatment: a new meta-analysis and review of the role of varicocele repair. Eur Urol 2011;60:796-808.

Affiliations: From the Pyrah Department of Urology (Forster), St. James's University Hospital, Leeds Teaching Hospitals NHS Trust, Leeds, UK; and the Department of Urology (Biyani), The Mid Yorkshire Hospitals NHS Trust, Wakefield, UK

Contributors: Both authors wrote and revised the manuscript, and approved the final version submitted for publication.

Decisions is a series that focuses on practical evidence-based approaches to common presentations in primary care. The articles address key decisions that a clinician may encounter during initial assessment. The information presented can usually be covered in a typical primary care appointment. Articles should be no longer than 650 words, may include one box, figure or table and should begin with a very brief description ( 75 words or less) of the clinical situation. The decisions addressed should be presented in the form of questions. A box providing helpful resources for the patient or physician is encouraged. 